\title{
Nanocrystalline structure and hardness of thin films
}

\author{
A. Cavaleiro*, C. Louro \\ Departamento de Engenharia Mecânica, Universidade de Coimbra, Polo II, ICEMS, FCTUC, Pinhal de Marrocos, \\ 3030 Coimbra, Portugal
}

\begin{abstract}
$\mathrm{W}-\mathrm{Si}-\mathrm{N}$ films were deposited by reactive sputtering in a $\mathrm{N}_{2}+\mathrm{Ar}$ atmosphere from a $\mathrm{W}$ target incrusted with different number of Si pieces. The coatings present different crystallographic structures from the crystalline $\alpha$-W and $\mathrm{W}_{2} \mathrm{~N}$ to amorphous phase. Crystalline films have very low grain sizes from 15 down to $3 \mathrm{~nm}$.

For W-Si films there is a good correlation between the increase of the hardness and both the increase of lattice parameter and decrease of grain size. However, for $\mathrm{N}$ containing films these tendencies are not systematically observed. The homogeneity in the lattice distortion seems to be more adequate to interpret the hardness variation.

Generally, crystalline films have higher hardness (35-41 GPa) than amorphous coatings (21-31 GPa). C 2002 Elsevier Science Ltd. All rights reserved.
\end{abstract}

Keywords: W-Si-N coatings; Hardness; Nanostructure; Sputtering

\section{Introduction}

It is well known the improvement on the strength of materials by grain refinement. The Hall-Petch equation relates the yield stress, and thus the hardness, with the inverse of the square root of the grain size (ø). However, many authors reported an inverse of this law when the grain size decreases down to values lower than $10-20 \mathrm{~nm}$ $[1,2]$. The softening observed was attributed to the high volume fraction of interfacial regions that leads to high deformation by different mechanisms of grain boundary sliding. Recently, other authors found that Hall-Petch relationship can be verified either for very low period multilayers [3] or in thin coatings of the system $\mathrm{M}-\mathrm{Si}-\mathrm{N}(\mathrm{M}=\mathrm{W}, \mathrm{Ti}, \mathrm{V})$

*Corresponding author. Tel.: + 351-23979-0745; fax: + 35123979-0701.

E-mail address: albano.cavaleiro@dem.uc.pt (A. Cavaleiro).
[4-6]. These last films were described as a nanocomposite consisting of nanocrystalline nitride phases (ø down to $3 \mathrm{~nm}$ ) in an amorphous silicon nitride matrix $\left(\mathrm{nc}-\mathrm{MN}_{x} / \mathrm{a}-\mathrm{SiN}_{x}\right)$ or in a crystalline phase matrix $\left(\mathrm{nc}-\mathrm{MN}_{x} / \mathrm{c}-\mathrm{MSi}_{x}\right.$ ) which had sufficient structural flexibility to form a strong interface. Very high hardness values (over $50 \mathrm{GPa}$ ) were obtained in nc-TiN/a-Si ${ }_{3} \mathrm{~N}_{4}$ coatings deposited by plasma CVD [5].

Sputtering is a well known deposition technique for the production of metastable structures, including amorphous and high temperature phases. With the appropriate selection of the deposition parameters it is possible to deposit compounds with a large range of grain sizes from hundreds down to a few nanometers or even amorphous structures.

Since some years ago we are being concerned with the development of hard coatings based on tungsten deposited by sputtering. Recently, we 
have been studying the system $\mathrm{W}-\mathrm{Si}-\mathrm{N}$ which, owing to its peculiarity, is a good example to analyse different type of parameters that are usually presented (including the grain size) to interpret the high hardness values obtained in thin coatings. In previous papers $[7,8]$ the results of the hardness of $\mathrm{W}-\mathrm{Si}-\mathrm{N}$ films were presented and discussed mainly as a function of their structure and annealing temperatures. Crystalline coatings showed higher hardness values than amorphous films.

The aim of this paper is to discuss and interpret the hardness results of $\mathrm{W}-\mathrm{Si}-\mathrm{N}$ coatings as a function of the structural parameters, such as grain size, lattice parameter and homogeneity degree in the lattice distortion. Moreover, the comparison with the literature results, particularly with the interpretation suggested above [4-6], will be discussed.

\section{Experimental details}

All the coatings were sputter coated in a Hartec d.c. magnetron sputtering apparatus; deposition was carried out at a power density of $11 \mathrm{~W} \mathrm{~cm}^{-2}$ and a negative substrate bias at $70 \mathrm{~V}$. The total gas pressure employed during the deposition was $0.3 \mathrm{~Pa}$; the samples containing $\mathrm{N}$ were deposited in a mixture of argon and nitrogen, with a partial pressure ratio $P_{\mathrm{N}_{2}} / P_{\mathrm{Ar}}$ in the range $(0-2)$ : the thickness of the films was in the range $(2-4 \mu \mathrm{m})$. In order to obtain different $\mathrm{Si}$ contents in the films ( $\mathrm{Si} / \mathrm{W}$ ratios in the range $0-1.2$ ) the $\mathrm{W}$ target was incrusted with an increasing number of Si pieces. These pieces were distributed symmetrically on the preferentially eroded zone of the target, following the magnetic field of the magnetron. The coatings were deposited on 310 refractory steel (AISI) and M2 high speed steel (AISI) substrates which were kept at temperatures close to $450^{\circ} \mathrm{C}$.

The chemical composition of the coatings was determined by Electron Probe Microanalysis (EPMA) with Cameca SX-50 equipment.

The structure of the films was analysed by X-ray Diffraction (XRD), using a Siemens Diffractometer with $\mathrm{Co} \mathrm{K}_{\alpha}$ radiation. As referred to for nanocrystalline $\mathrm{Ti}-\mathrm{Si}-\mathrm{N}$ system [6], the grain size was determined applying the Scherrer formula with the integral width of the main diffraction peak.

The hardness tests were performed in an ultramicroindentation device Fischerscope H100, with a Vickers indenter and a maximum indentation load of $50 \mathrm{mN}$. Each hardness value is a result of at least five indentation tests. The hardness results were corrected in relation to the geometrical defects of the indenter, the thermal drift and the uncertainty in zero position [9].

\section{Results and discussion}

\subsection{W-Si system}

Crystalline $\mathrm{W}-\mathrm{Si}$ films were deposited with $\mathrm{Si}$ contents in the range 1 to 5 at. $\%$. All the coatings showed the bcc $\alpha-\mathrm{W}$ phase. The influence of $\mathrm{Si}$ content on the hardness of $\mathrm{W}-\mathrm{Si}$ films deposited on both M2 and 310 steels is shown in Fig. 1. Moreover, the evolutions of the grain size $\left(\varnothing_{h k l}\right)$ and lattice parameter $\left(a_{h k l}\right)$ of the films with the increasing incorporation of silicon are also presented. As it was expected, the analysis of this figure allows to conclude that the increase of the hardness is related either to the decrease of grain size or the increase of lattice parameter. Since long time ago, the Hall-Petch equation justified quite well the increase of the hardness with the grain size decrease $(>100 \mathrm{~nm})$ and it was based on the pile up of dislocations on grain boundaries [1,5]. For lower grain sizes, dislocations are scarce and the grain boundary sliding determines the material deformation [1]. Thus, a "reverse" Hall-Petch relationship can be observed with the consequent softening of the material with grain size decrease. However, if a strong interface between the grains occurs during the material formation, the grain boundary sliding can be avoided and the strength and hardness will increase.

For very low grain sizes $(<10 \mathrm{~nm})$ the atomic forces and the Griffith theory of crack growth should be considered to explain the strength of a material [5]. Following this theory, the critical stress for the growth of a crack is inversely related to its size and thus the strength of a material can 

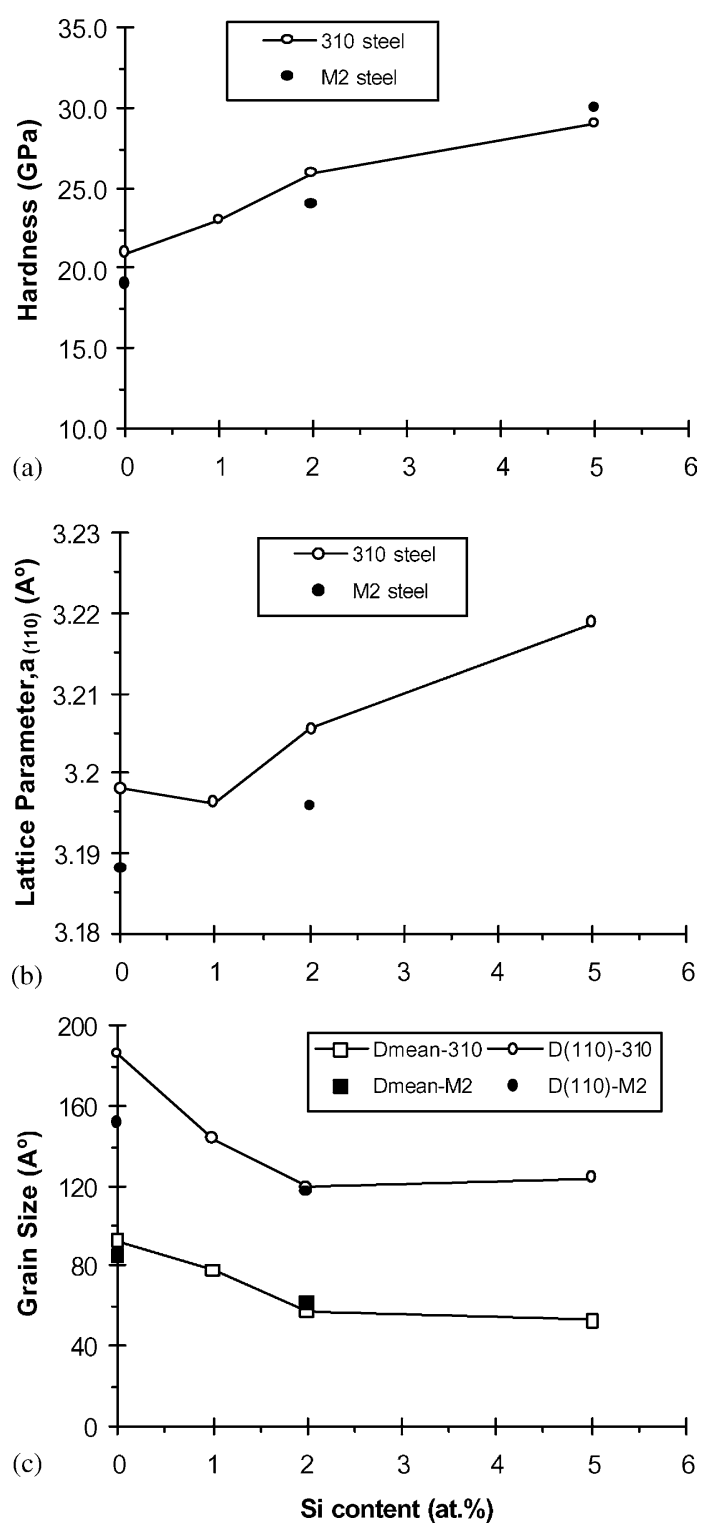

Fig. 1. Influence of the Si content on the (a) hardness, (b) lattice parameter and (c) grain size, of $\mathrm{W}-\mathrm{Si}$ sputtered films.

be improved if the size of the cracks can be limited to very small values (a few nanometers). As a consequence, in nanocrystalline materials, if both the grains and the grain boundaries are strong enough impeding the crack growth, the size of the cracks are very small (dimensions of the grains or the interfaces) and very high strength can be obtained. The lower their dimensions the higher will be the hardness of the materials. The very low grain size $(80-150 \mathrm{~nm})$ can contribute to justify the very high hardness value of the $\mathrm{W}$ sputtered film $(20 \mathrm{GPa})$ in comparison with bulk material (3 GPa). Moreover, the increase in the interplanar distances of the W film (e.g. $d_{(110)}=2.2614 \AA$ against $d_{\left(\begin{array}{lll}1 & 1 & 0\end{array}\right)=2.2380 \AA \text { in ICDD standard [10]) }}$ suggests a high level of residual compressive stresses in the coatings that contributes also to explain the high hardness of this film. The compressive stresses arise either from thermal expansion coefficients misfit between the film and the substrate $\left(\alpha_{\mathrm{W}}=4.5 \times 10^{-6} \mathrm{~K}^{-1}, \alpha_{310}=\right.$ $\left.17 \times 10^{-6} \mathrm{~K}^{-1}, \alpha_{\mathrm{M} 2}=13 \times 10^{-6} \mathrm{~K}^{-1}\right)$ during the cooling from the deposition temperature $\left(450^{\circ} \mathrm{C}\right)$ or from intrinsic reasons related to the bombardment of the coatings during deposition. Owing to the low deposition pressure and negative substrate bias used in the deposition, energetic particles (ions, neutrals reflected on the target,...) reach the growing film with enough energy to be incorporated in the film, giving rise to the so called "atomic peening effect" [11]. It is worthily to remark the good agreement between the hardness values of the same coating deposited on the two different steel substrates and the lattice parameter. The hardness is higher for the film deposited on the 310 steel in agreement to its higher lattice parameter (Fig. 1a and b), probably due to the higher compressive stress level induced by the higher misfit in the thermal expansion coefficients values in relation to the M2 steel.

The incorporation of $\mathrm{Si}$ in the $\alpha-\mathrm{W}$ lattice in interstitial positions [12], gives rise to an increase of the compressive stress level as suggested by the increase in $a_{h k l}$ values. Moreover, a decrease in the grain size was also observed. Thus, higher hardness values were found for these coatings.

\section{2. $W-N$ system}

The films of the $\mathrm{W}-\mathrm{N}$ system have the bcc $\alpha-\mathrm{W}$ structure for $\% \mathrm{~N}<20$ at $\%$, the fcc $\mathrm{W}_{2} \mathrm{~N}$ for $\% \mathrm{~N}>35$ at $\%$ and a mixture of these two phases for intermediate $\mathrm{N}$ contents. As observed for the $\mathrm{W}-\mathrm{Si}$ system, the addition of $\mathrm{N}$ has also a 
significant influence on the hardness of $\mathrm{W}$ sputtered films (Fig. 2). For comparison, in this figure are also shown results obtained previously in another work [13] for the same type of films deposited on M2 steel. The same factors indicated above to justify the increase of the hardness with $\mathrm{Si}$ addition can be used in the case of $\mathrm{W}-\mathrm{N}$ films. However, other points should be taken into account. In fact, after the strong increase of the hardness for $5 \mathrm{at} \% \mathrm{~N}$, although the $a_{h k l}$ values continue to increase and the grain size to decrease, there is a softening in the films. A parameter that has been referred to in the literature as having a great influence in the strength of a coating is the anisotropy degree in the distortion of the lattice. Several authors $[14,15]$ have found that the dilatation of the lattice is only effective in determining the hardness of a coating, if it is homogeneous in all the directions. Even if very great distortions are found in one set of crystallographic planes, the consequent hardness increase is only significant if congruent lattice deformation is observed in all the directions. As can be remarked from Fig. 2d, for $11 \mathrm{at} \% \mathrm{~N}$, the decrease in the hardness corresponds to an increase in the anisotropy in the lattice distortion. Similar behaviour was found by Quesnel et al. [15] for $\mathrm{W}-\mathrm{C}$ coatings with the bcc $\alpha-\mathrm{W}$ structure. Up to $14 \mathrm{at} \%$ $\mathrm{C}$ the hardness increased with uniform dilatation of lattice parameter; for higher $\mathrm{C}$ values the expansion of the lattice became anisotropic and a drastic decrease in the hardness was detected.

\section{3. $W-S i-N$ system}

In the case of the simultaneous addition of $\mathrm{Si}$ and $\mathrm{N}$, three different structures must be considered: the films with the bcc $\alpha$-W phase, those with the fcc $\mathrm{W}_{2} \mathrm{~N}$ nitride and the amorphous films.

In the first case, the films show a good agreement with the trends shown in the curves of Fig. 2 for $\mathrm{W}-\mathrm{N}$ system. It is only worthily to remark the case of $\mathrm{W}_{76} \mathrm{Si}_{12} \mathrm{~N}_{12}$ film, presenting the highest hardness found for the as-deposited $\mathrm{W}-\mathrm{Si}-$ $\mathrm{N}$ films, 41 and $45 \mathrm{GPa}$ when deposited on 310 and M2 steels, respectively. In relation to Fig. 2, the hardness values are higher than those obtained for similar $\mathrm{N}$ contents. In spite of the small increase
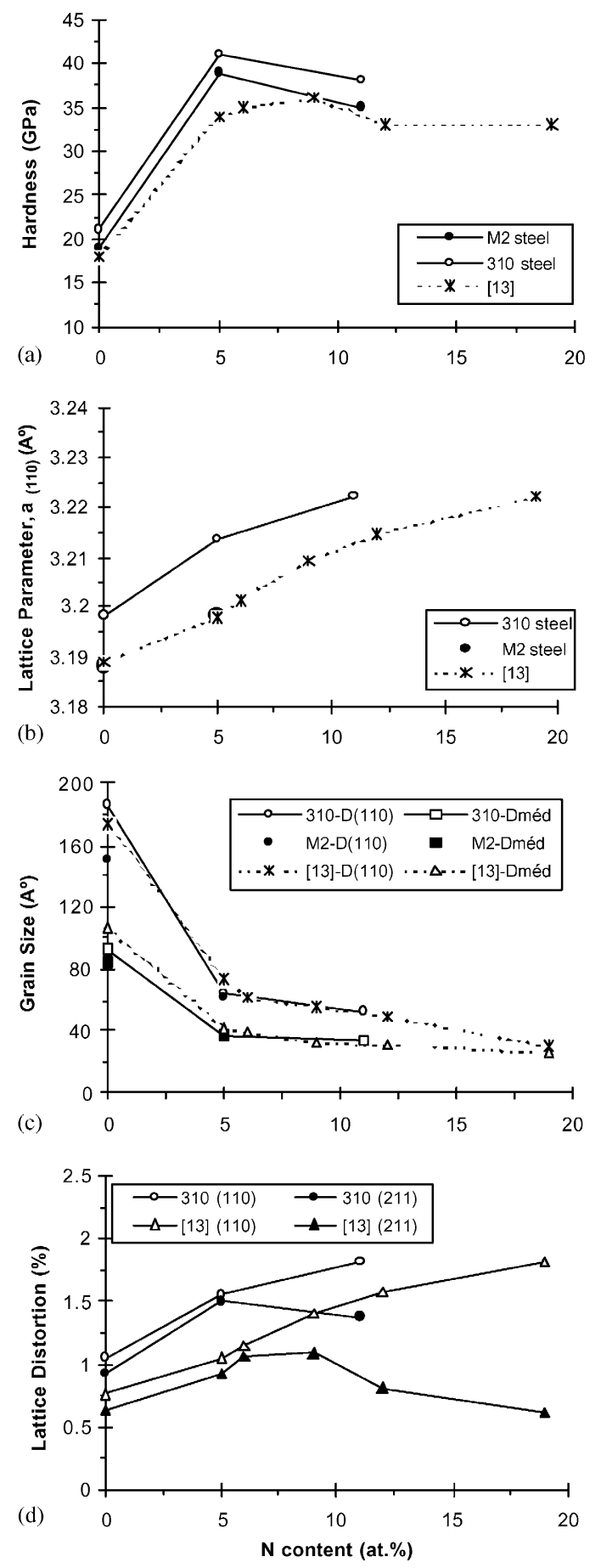

Fig. 2. Influence of the $\mathrm{N}$ content on the (a) hardness, (b) lattice parameter, (c) grain size and (d) lattice distortion, of $\mathrm{W}-\mathrm{N}$ sputtered films. 
of the lattice parameter $\left(a_{h k l}=3.23 \AA\right.$ against the $3.22 \AA$ expected from the trend) both the higher grain size $(80 \AA$ against $50 \AA)$ and the higher anisotropy in the lattice distortion ([1.2-2.1\%] against [1.3-1.7\%]) suggest a decrease in the hardness. The unique structural detail which is very different in this film in comparison to $\mathrm{W}-\mathrm{N}$ films is its preferential orientation (Fig. 3). Although all the other films have a [1 10 l preferential growth, this film has a very strong [2 11 ] orientation, which is higher for the film deposited on M2 than for 310 steel (as it is the hardness).

The influence of the preferential orientation on the hardness values can be analysed in the light of the plastic deformation of materials. The higher is the resistance to plastic deformation the harder the material. The critical shear stress for a slip system can be obtained from [16]

$\tau=\sigma \cos \phi \cos \lambda$,
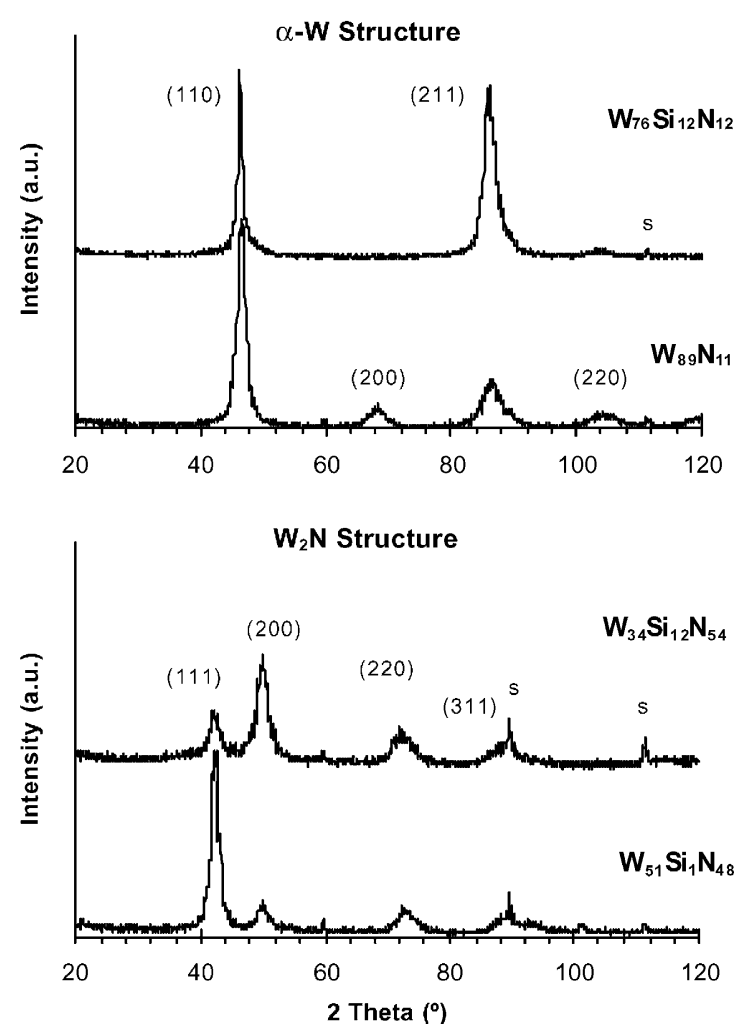

Fig. 3. X-ray diffractograms of $\mathrm{W}-\mathrm{Si}-\mathrm{N}$ sputtered films (s-substrate). where $\sigma$ is the applied stress, $\tau$ the shear stress in a slip plane, $\phi$ the angle between the directions of the applied stress and the normal to slip plane, $\lambda$ the angle between the directions of the applied stress and the slip; $m=\cos \phi \cos \lambda-$ Schmid factor.

It is possible to have an idea of the $\sigma$ value to reach a critical shear stress value in order to begin the plastic deformation, if the Schmid factor, $m$, is known. For bcc materials the slipping systems are not so well defined as for hc and fcc; however, is usually accepted [16] that slip can occur in all the planes containing the close packed direction $\left\langle\begin{array}{lll}1 & 1\end{array}\right\rangle$. Thus, if the stresses are applied normally to the film surface (as it would be expected in the

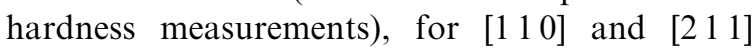
orientations the Schmid factor is 0.46 and 0.40 , respectively. Thus, if the planes (2 11 ) are parallel to the surface, a higher stress must be applied to reach the critical shear stress and, consequently, a higher hardness value must be obtained. As $\mathrm{W}_{76} \mathrm{Si}_{12} \mathrm{~N}_{12}$ film is preferentially oriented following [2 111$]$ direction, its hardness should be higher than for $\mathrm{W}-\mathrm{N}$ films, which are $\left[\begin{array}{lll}1 & 1 & 0\end{array}\right]$ oriented.

Fig. 4 presents the influence of the $\mathrm{Si}$ content on the hardness of $\mathrm{W}-\mathrm{Si}-\mathrm{N}$ films $\left(\mathrm{W}_{45} \mathrm{~N}_{55}\right.$, $\mathrm{W}_{51} \mathrm{Si}_{1} \mathrm{~N}_{48}, \quad \mathrm{~W}_{50} \mathrm{Si}_{3} \mathrm{~N}_{47}, \quad \mathrm{~W}_{49} \mathrm{Si}_{4} \mathrm{~N}_{47} \quad$ and $\mathrm{W}_{34} \mathrm{Si}_{12} \mathrm{~N}_{54}$ ) with $\mathrm{W}_{2} \mathrm{~N}$ structure. If these results are compared to those of literature either for $\mathrm{W}-$ $\mathrm{Si}-\mathrm{N}$ [5] or Ti-Si-N [17] systems (Fig. 5), it can be concluded that the evolutions are quite different. Veprek [5] found the maximum hardness value for Si contents of $8-9$ at $\%$. At that time, they justify this behaviour to the minimum grain size reached at that point. However, later on [18] they referred that, although the grain size is important, the main parameter to be considered was the percolation limit that was attained for that Si content. They found in later research works [18] for $\mathrm{Ti}-\mathrm{Si}-\mathrm{N}$ system that the grain size could decrease with $\mathrm{Si}$ content increase, but the maximum hardness was always reached for values close to $8-9 \mathrm{at} \%$. The same is shown in Fig. 5 for the results of Vaz [17], who have also presented a similar explanation for this behaviour.

In the case of the present study the maximum hardness $(42 \mathrm{GPa})$ is reached for only $1 \mathrm{at} \% \mathrm{Si}$ (Fig. 4), being noted a decrease in the hardness for higher Si contents, with the lowest value deter- 


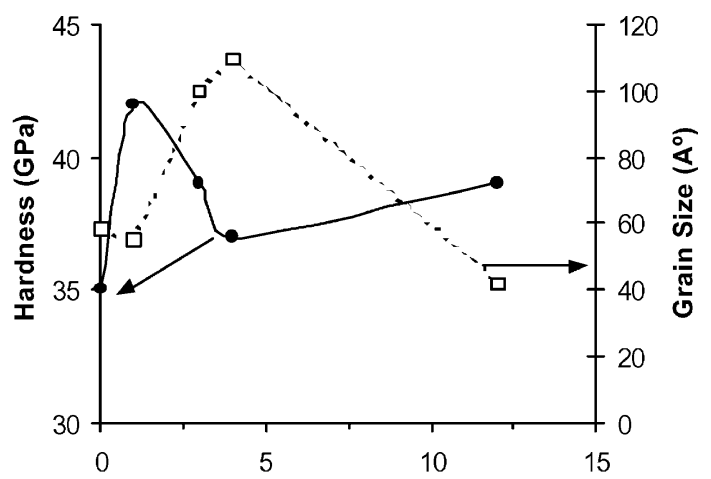

(a)

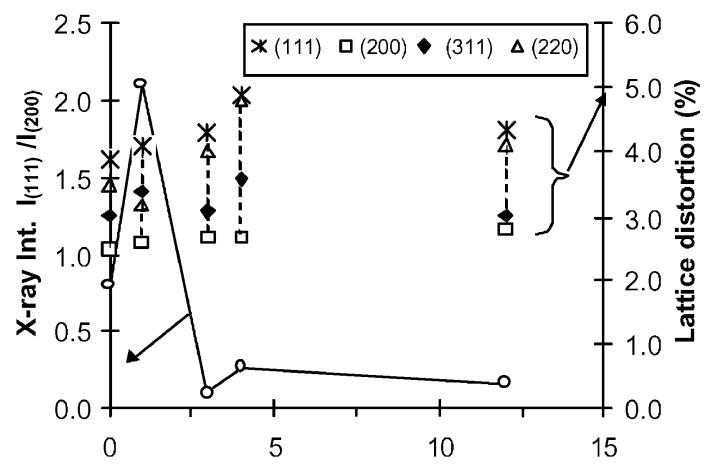

(b)

Si content (at.\%)

Fig. 4. Influence of the Si content on the (a) hardness and grain size, (b) preferential orientation and lattice distortion, of $\mathrm{W}-\mathrm{Si}-\mathrm{N}$ sputtered films.

mined on the film with 8 at $\%$ Si. This evolution invalidates any tentative to explain the hardness results based on that theory.

The analysis of Fig. 4 allows to conclude that the influence of the structural parameters, indicated above on the mechanical behaviour of the coatings, can one time more be used to interpret these results. Firstly, the small addition of Si lead to an increase in the lattice parameter, suggesting a higher compressive stress level. However, this should not be determinant since for higher $\mathrm{Si}$ contents, the $a_{h k l}$ values continue to increase and the hardness decreases. What seems to really matter is the preferential orientation of the $\mathrm{W}_{51} \mathrm{Si}_{1} \mathrm{~N}_{48}$ film (Figs. 3 and $4 \mathrm{~b}$ ). Contrarily to the others, this film shows a very strong orientation, [1 111$]$ instead of [2 00 0]. Recently, Ljungcrantz et al. [19] deposited TiN coatings epitaxially on

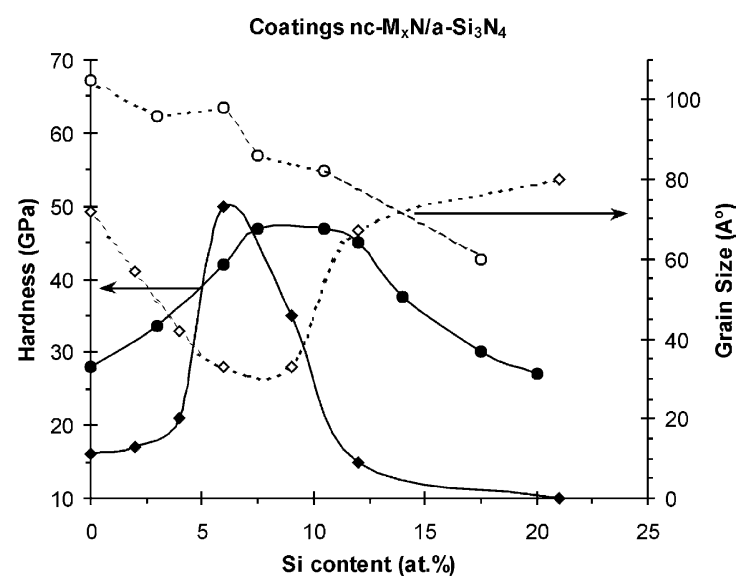

Fig. 5. Influence of the $\mathrm{Si}$ content on the hardness and grain size of $\mathrm{W}-\mathrm{Si}-\mathrm{N}(\diamond, \diamond)[5]$ and $\mathrm{Ti}-\mathrm{Si}-\mathrm{N}(\bigcirc, \bullet)[17]$ films.

$\mathrm{MgO}$ substrates differently oriented. By calculating the Schmid factors for the particular case of fcc $\mathrm{NaCl}$ type structure of TiN, they obtained higher critical shear stresses for plastic deformation in the case of (1 111$)$ oriented films. In agreement, the experimental hardness values for TiN films grown with (llll 111$)$ orientation were harder than the other films. As $\mathrm{W}_{2} \mathrm{~N}$ is isomorphous of $\mathrm{TiN}$, a similar behaviour can be expected which can explain the higher hardness of the film with $1 \mathrm{at} \%$ of $\mathrm{Si}$. Moreover, as Fig. $4 \mathrm{~b}$ shows, this is one of these films presenting a lower anisotropy in the distortion of the lattice parameters calculated from the different crystallographic planes.

The increase in the grain size should be considered to explain the decrease in the hardness observed for $\mathrm{Si}$ contents in the range $[1-4 \mathrm{at} \% \mathrm{Si}]$. As presented in Fig. 4a, there is a good relationship between the increase in the grain size (from 55 to $110 \AA$ ) and the decrease in the hardness (from 42 to $37 \mathrm{GPa}$ ) for the films with 1,3 and $4 \mathrm{at} \% \mathrm{Si}$. Finally, it should be remarked that the lowest hardness was found for $\mathrm{W}_{49} \mathrm{Si}_{4} \mathrm{~N}_{47}$ film, which presents the highest anisotropy in the lattice distortion, similarly to the results of Quesnel et al. [15] for sputtered coatings from the $\mathrm{W}-\mathrm{C}$ system with $\beta-\mathrm{WC}_{1-x}$ $\mathrm{NaCl}$ type structure. These authors found the lowest hardness values in the films presenting the greatest differences in the lattice parameters values calculated from several crystallographic planes. 


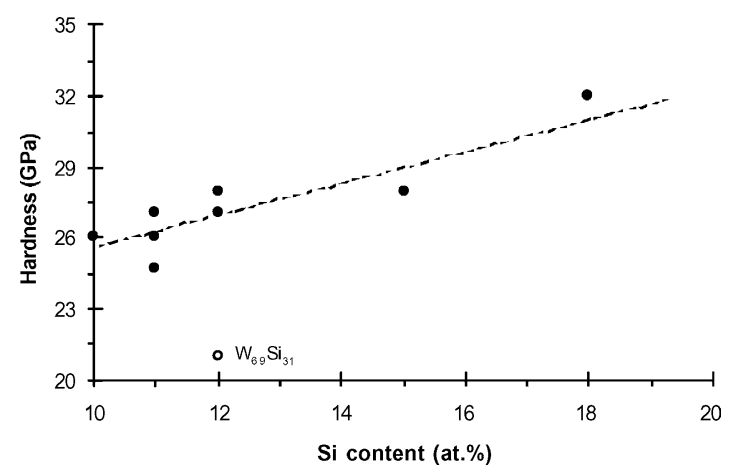

Fig. 6. Influence of the size of the short range order agglomerates on the hardness of $\mathrm{W}-\mathrm{Si}-\mathrm{N}$ sputtered amorphous films.

Generally, $\mathrm{W}-\mathrm{Si}-\mathrm{N}$ amorphous films are softer than crystalline films. This tendency was already observed for sputtered coatings of other systems, such as $\mathrm{W}-\mathrm{C}-\mathrm{Co}[20], \mathrm{Ni}-\mathrm{Cr}-\mathrm{N}$ [21] and $\mathrm{W}-\mathrm{Ni}-\mathrm{N}$ [22]. The lower hardness values of amorphous films can be probably related to their lower compressive stress state. The evaluation of the stresses in $\mathrm{W}-\mathrm{Si}-\mathrm{N}$ coatings was not the aim of this study. However, in another study on the deposition of $\mathrm{W}-\mathrm{N}$ sputtered films, it was demonstrated that the stresses diminish considerably when the coatings change their structure from crystalline to amorphous [23]. Moreover, for $\mathrm{W}-\mathrm{C}-\mathrm{Co}$ coatings [20], there were clear indications, during the scratch testing of the films (tensile cracking instead of conformal cracking), of lower compressive stresses in amorphous than in crystalline coatings. Another point which is worthily to consider is the size of the short range order agglomerates characteristics of this type of structure. If the above referred "reverse" Hall-Petch behaviour is taken into account, it should be expected that for sufficiently low grain sizes $(<2-$ $3 \mathrm{~nm}$ ) a decrease in the hardness must be detected with decreasing grain size. Thus, inversely, departing from the amorphous disorder, an improvement of the hardness must be found with increasing order in the structure. This tendency was observed as can be verified in Fig. 6, on which the hardness is plotted against the dimensions of the agglomerates calculated by applying the Scherrer equation to the main diffraction peak of the amorphous films.

\section{Conclusions}

- $\mathrm{W}-\mathrm{Si}-\mathrm{N}$ films were deposited by sputtering from a tungsten target superimposed with $\mathrm{Si}$ plates, with increasing partial pressures of nitrogen.

- For crystalline $\mathrm{W}-\mathrm{Si}$ films the hardness increases with increasing $\mathrm{Si}$ addition. This behaviour was interpreted owing to increasing lattice parameter and decreasing grain size.

- Similar behaviour was found for $\mathrm{W}-\mathrm{N}$ films with $\alpha-\mathrm{W}$ structure, for low $\mathrm{N}$ contents $(<5$ at $\%)$. However, for higher $\mathrm{N}$ contents, in spite of the higher $a_{h k l}$ and lower $\varnothing_{h k l}$ values, the decrease of the hardness was explained by the anisotropy in the lattice distortion.

- For $\mathrm{W}-\mathrm{Si}-\mathrm{N}$ films, besides these structural parameters, it was necessary to consider the preferential orientation of the coatings to explain the hardness variations. Hence, either the films with bcc $\alpha-\mathrm{W}$ structure or the films with fcc $\mathrm{W}_{2} \mathrm{~N}$ were harder when their orientation was

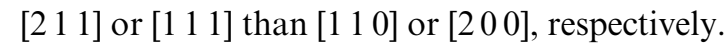

- The hardness of the amorphous $\mathrm{W}-\mathrm{Si}-\mathrm{N}$ films was lower than that of the crystalline films and it increases with increasing size of the short range order agglomerates.

\section{References}

[1] Musil J, Vlcek J. Czech J Phys B 1998;48:10.

[2] Weertman JR, Farkas D, Hemker K, Kung H, Mayo M, Mitra R, Van Swygenhoven H. MRS Bull 1999;24:44.

[3] Clemens BM, Kung H, Barnett SA. ibid 1999;24:20.

[4] Veprek S, Haussmann M, Reiprich S. J Vac Sci Technol A 1996;14:46.

[5] Veprek S. Thin Solid Films 1997;297:145.

[6] Niederhofer A, Nesladek P, Mannling HD, Moto K, Veprek S, Jilek M. Surf Coat Technol 1999;120-121:173.

[7] Louro C, Cavaleiro A. Surf Coat Technol 1999; 116-119:198.

[8] Louro C, Cavaleiro A. Surf Coat Technol 2000;123:192.

[9] Antunes JM, Cavaleiro A, Menezes LF, Simões MI, Fernandes JV. Surf Coat Technol, submitted for publication.

[10] International Center for Diffraction Data, Pennsylvania, Cards 4-0806.

[11] Thornton JA. J Vac Sci Technol A 1986;4:3059.

[12] Cristina Louro, Ph.D. thesis, Faculdade de Ciências e Tecnologia da Universidade de Coimbra, Portugal, 2000. 
[13] Cavaleiro A, Trindade B, Vieira MT. Improvement of the performance of $(\mathrm{W}-\mathrm{C} / \mathrm{N})$-based coatings by Ti addition, communication presented at ICMCTF-99, San Diego, USA, 1999.

[14] Rudnik PJ, Graham ME, Sproul WD. Surf Coat Technol 1991;49:293.

[15] Quesnel E, Paulean Y, Monge-Cadet P, Brun M. Surf Coat Technol 1993;62:473.

[16] Fernandes JV, Schmitt JH. Philos Mag A 1983;48:841.

[17] Filipe Vaz, Ph.D. thesis Universidade do Minho, Portugal, 2000 .
[18] Veprek S. J Vac Sci Technol A 1999;17:2401.

[19] Ljungcrantz H, Odén M, Hultman L, Greene JE, Sundgren J-E. J Appl Phys 1996;80:6725.

[20] Cavaleiro A, Vieira MT. Surf Eng 1994;10:147.

[21] Musil J, Regent F, Symposium Proceedings on Plasma Chemistry, 14th International Symposium, vol. III. Praha, Républica Checa, 1999. p. 1617.

[22] Cavaleiro A, Trindade B, Vieira MT. Surf Coat Technol 1999; 116/119:944.

[23] So FCT, Kolawa E, Zhao XA, Nicolet MA. Thin Solid Films 1987;153:507. 